\title{
Simulation of SOFC stack and repeat elements including interconnect degradation and anode reoxidation risk
}

\author{
D. Larrain*, J. Van herle, D. Favrat \\ Laboratory for Industrial Energy Systems (LENI), Faculty of Engineering, Ecole Polytechnique Fédérale de Lausanne, 1015 Lausanne, Switzerland
}

Received 22 November 2005; received in revised form 11 March 2006; accepted 10 April 2006

Available online 11 July 2006

\begin{abstract}
Reliability of SOFC stacks is a complex and key issue. This paper presents a simulation study including some degradation processes, namely interconnect degradation and the anode reoxidation potential. Quantification for these phenomena has been included in a repeat element model to simulate stack degradation and study the influence of design and operating parameters on the degradation.

Interconnect degradation is based on Wagner's law for oxide scale growth, parameters applying to metallic interconnects used in planar SOFCs are used. Anode reoxidation is modeled by thermodynamic equilibrium which allows identification of the operating conditions where the anode is likely to be reoxidized.

Simulations have been carried out for a large number of cases at different current density, fuel utilization and furnace temperature, for two different stack designs (base case and modified design). Using an appropriate criterion to express degradation, all these cases point to a clear trade-off between interconnect degradation and local temperature. The base case design is likely to be exposed to anode reoxidation.
\end{abstract}

(C) 2006 Elsevier B.V. All rights reserved.

Keywords: Solid oxide fuel cell; Modeling; Degradation; Interconnect; Stack

\section{Introduction}

Lifetime of the systems is a major issue for SOFCs towards commercial use. Lifetime is limited by the risk of failure of the stacks or system components. Failure of components is not the only problem since degradation of stack and cell performance is observed during long term operation. This decline in performance is related to the different physicochemical processes taking place in the repeat element components.

Some of these processes are well identified while others are still being discussed. Operating conditions, in terms of furnace temperature, current density and cell potential, seem to have an influence on the degradation rate but this is not fully identified. In a stack, degradation is not homogeneous on the whole active cell surfaces, and considering that degradation phenomena are cumulated, the degradation behavior measured in stacks is difficult to interpret. Simulation of degradation could provide insight. Among the possible processes, we selected those which

\footnotetext{
* Corresponding author. Tel.: +41 2169335 10; fax: +41 216933502.

E-mail address: diego.larrain@a3.epfl.ch (D. Larrain).
}

are sufficiently well characterized and understood to be included in a model. In this work, interconnect degradation is considered.

The paper first summarizes degradation processes and the possibility of simulating them in a repeat element model is evaluated. Then, a model for metal interconnect degradation is introduced leading to simulation results for repeat element and stack long term operation. The influences of operating conditions and design options have been included.

\section{Degradation phenomena}

Aging of the different materials composing a SOFC stack occurs intrinsically at SOFC operating temperatures. Depending on the component, different phenomena combine to modify the materials properties and microstructure, with the common effect of decreasing the electrochemical performance of the stack.

\subsection{Electrode and electrolyte degradation}

For electrodes, different phenomena are recognized. Impurities tend to aggregate at the triple phase boundary (TPB) and grain size tends to grow. On the cathode side, new phases can be 
produced at the interface with the electrolyte for LSM cathodes [1-3]. LSF cathodes, which are used more recently in the intermediate temperature range, are subject to diffusion of $\mathrm{Zr}$ cations from the electrolyte [4], thus reducing their electronic conductivity. Microstructural changes have been reported for LSM cathodes under load [5]. Similar studies for LSF cathodes are not yet published. On the anode side, nickel sintering causes a decrease in TPB length [6,7]. The purity of starting powders has an influence on the impurity formation at the TPB [8]. Mobility of nickel can be attributed to formation of $\mathrm{Ni}(\mathrm{OH})_{2}$ at high $p_{\mathrm{H}_{2} \mathrm{O}}$ [6].

No reliable quantification for the degradation of electrodes is available. Degradation is dependent on the primary materials and the manufacturing procedures.

The commonly used 8YSZ electrolyte is known to exhibit a decrease in conductivity with time [9-11] that is explained by the phase transformation from cubic to tetragonal [10]. Degradation is ca. $25 \%$ in the first $1000 \mathrm{~h}$ of operation for the temperature range of $950{ }^{\circ} \mathrm{C} / 1000{ }^{\circ} \mathrm{C}$, then the rate of degradation drops [11]. Differences in reported degradation rates could be explained by the different starting materials and manufacturing processes. Moreover, the available data on degradation concern pure electrolyte material while for anode supported cells the electrolyte is subject to a contamination with nickel which has a significant effect on the conductivity behavior [12]. The data available on the electrolyte are not sufficient to be implemented in a model as neither the dependence with temperature nor the modification of the behavior with impurities is identified.

Degradation of electrodes and electrolytes cannot yet be implemented in a model as the phenomena are neither fully understood nor quantified.

\subsection{Metallic interconnect degradation}

For metallic interconnects, high temperature conditions induce the growth of an oxide scale on the surface of the interconnect [13]. This oxide scale has poorer conductive properties than the metal and therefore the contact resistance between the current collectors and the interconnect is affected. Oxidation of the interconnect is also observed under fuel atmosphere simulating high fuel utilization [14]. Finally, chromium evaporation has been measured especially in air [15]; chromium can be reduced (from valence VI+ to III+) at the cathode triple phase boundary, reducing the TPB length and the electrode performance, but this effect is lowered when operating in the intermediate temperature range.

Lowering the operating temperature in SOFCs allows the use of ferritic steel alloys instead of more costly chromium based alloys used at higher temperature [14,16]). The requirements for the interconnect material can be summarized as $[13,14]$ :

- oxide scale interface stability in both fuel and oxidant atmosphere, the oxide scale having to remain dense and without cracks to avoid an increase in the oxidizing surface;

- thermal expansion coefficient (TEC) close to the cell's TEC;

- sufficient electrical conductivity for the oxide scales formed on the surface.

The critical specification for the interconnect is the ohmic resistance of the system current collectors/interconnect. The

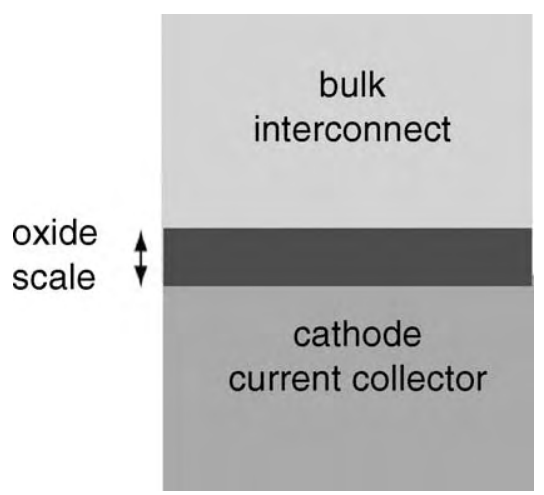

Fig. 1. Scheme representing the oxide scale formed at the interface between the interconnect and the cathode. The thickness and conductivity of the oxide scale are considered in the model.

Table 1

Composition of the tested interconnects

\begin{tabular}{lll}
\hline & Crofer22 & T458 \\
\hline $\mathrm{Cr}$ & 22.5 & 18.25 \\
$\mathrm{Fe}$ & $\mathrm{Bal}$ & $\mathrm{Bal}$ \\
$\mathrm{C}$ & 0.03 & 0.009 \\
$\mathrm{Al}$ & 0.1 & 0.03 \\
$\mathrm{Mn}$ & 0.5 & 0.4 \\
$\mathrm{Si}$ & 0.5 & 0.55 \\
$\mathrm{Ti}$ & 0.2 & 0.1 \\
$\mathrm{La}$ & 0.2 & - \\
$\mathrm{Cu}$ & 0.5 & - \\
$\mathrm{Nb}$ & - & 0.25 \\
$\mathrm{Ni}$ & - & 0.22 \\
\hline
\end{tabular}

ohmic resistance is here dominated by the contact resistance due to the oxide scale formed at the interface (see Fig. 1).

Ferritic steels have been investigated as potential candidates for the metallic interconnect, with chromium content generally between 18 and $26 \%$ in order to approach the thermal expansion coefficient of the cell. Minor components such as Mn, Ti, La and $\mathrm{Y}$ have been shown to have a strong impact on the conductivity of the oxide scale formed at the interface. Two alloys were compared [17] and the one showing the larger growth rate for the oxide scale showed a better conductivity: this is attributed to the spinel rich scale forming in this alloy-the spinel phase being more conductive than chromium oxide. A number of different commercial and experimental interconnect alloys have been tested in our facilities (composition in Table 1). Fig. 2 shows the area specific resistance measured as a function of time for some of the tested samples exposed to air at $800^{\circ} \mathrm{C}$. Three of these materials were used as interconnect materials in repeat element and stack testing.

\section{Interconnect degradation modeling}

\subsection{Model for a simple oxide scale growth}

The interconnect/current collector interface conductivity degradation can be described by a simple Wagner's law for oxide scale growth. This assumes that transport of the oxide form (e.g. $\mathrm{Cr}_{2} \mathrm{O}_{3}$ for chromium forming scale) takes place by lattice dif- 


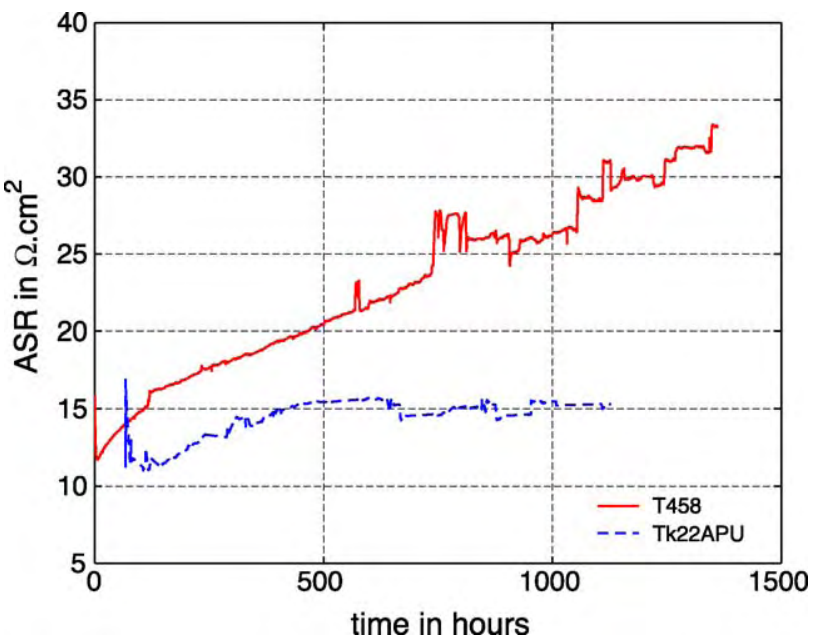

Fig. 2. Interconnect degradation at $800^{\circ} \mathrm{C}$, expressed on the base of the contact area.

fusion [18]. With these assumptions, the scale growth can be described by a simple parabolic law $[18,13,17]$ expressed as:

$\frac{\partial \xi^{2}}{\partial t}=\frac{k_{\mathrm{g}}^{\circ}}{\left(\chi \rho_{\mathrm{ox}}\right)^{2}} \mathrm{e}^{-E_{\mathrm{ox}} / R T}$

where $\xi$ is the scale thickness (in $\mathrm{cm}$ ), $\chi$ the oxygen weight proportion in the oxide formed, $\rho_{\mathrm{ox}}$ the oxide density $\left(5.22 \mathrm{~g} \mathrm{~cm}^{-3}\right.$ for $\left.\mathrm{Cr}_{2} \mathrm{O}_{3}\right)$ and $k_{\mathrm{g}}^{\circ}$ and $E_{\mathrm{ox}}$ are the weight gain rate constant and activation energy for the oxide scale growth, respectively. Values for the weight gain growth constant are in the range of $0.3-4 \times 10^{-12} \mathrm{~g}^{2} \mathrm{~cm}^{-4} \mathrm{~s}^{-1}$ ) while the activation energy for the scale growth is ca. $220 \mathrm{~kJ} \mathrm{~mol}^{-1}$ [13]. The rate constant can be expressed in terms of thickness following the equation:

$k_{\mathrm{p}}=\frac{k_{\mathrm{g}}^{\circ}}{\left(\chi \rho_{\mathrm{ox}}\right)^{2}}$

where $k_{\mathrm{p}}$ is the rate constant for the thickness growth of the scale. From the scale thickness and the oxide scale conductivity, the area specific resistance (ASR) for the oxide scale formed can be expressed:

$\mathrm{ASR}=\frac{\xi}{\sigma_{\mathrm{ox}}}$

$\sigma_{\text {ox }} T=\sigma_{\text {ox }}^{0} \mathrm{e}^{-E_{\mathrm{el}} / R T}$

where $\sigma_{\mathrm{ox}}$ is the conductivity of the scale (in $\mathrm{S} \mathrm{cm}^{-1}$ ), $\sigma_{\mathrm{ox}}^{0}$ the conductivity constant and $E_{\mathrm{el}}$ is the activation energy for the conductivity.

In cases where mixed ionic protective layers are used, this simple expression is not valid [18] and alternative expressions

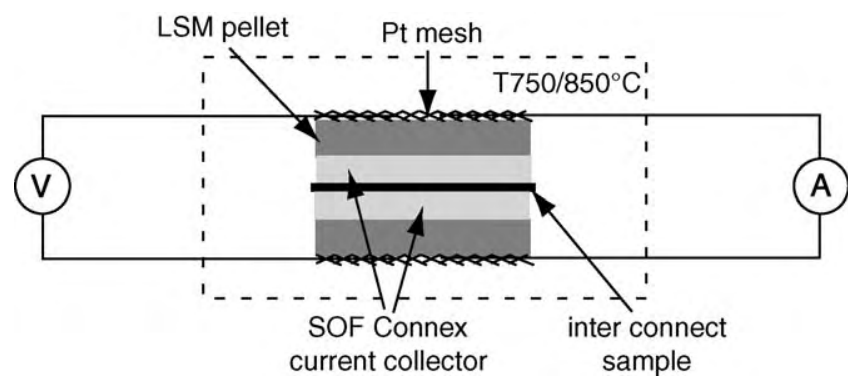

Fig. 3. Measurement set-up for interconnect conductivity.

are needed. Concerning Crofer22APU, which has been tested and used in our case, some authors claim that the growth rate cannot be fitted with a simple parabolic law [19] whereas others showed a good fit with the same parabolic law [17]. The resulting area specific resistance depends not only on the thickness of the layer but also on the conductivity of the oxide formed. Spinel oxides have a better conductivity than chromium oxide. For chromium scale, the conductivity is expected to be in the range of $10^{-3}$ to $10^{-2} \mathrm{~S} \mathrm{~cm}^{-1}$ at $800^{\circ} \mathrm{C}$ [13], whereas for spinel, values in the range of $10^{-2}$ to $1 \mathrm{~S} \mathrm{~cm}^{-1}$ are reported [20]. For the spinel phase, conductivity depends on composition.

The present work will use the simple growth rate model. It is considered to be sufficient and has been implemented in the stack model for the cathode current collector interface on the whole stack surface. The rate of growth on the interconnect is therefore dependent on the local interconnect temperature. In this work, an estimation of the following parameters has been performed from the experiments: activation energy of the scale conductivity $E_{\mathrm{el}}$, the constant for the scale conductivity $\sigma_{\mathrm{ox}}^{0}$, the rate constant for the thickness $k_{\mathrm{p}}$.

Conductivity measurements have been performed with a four-point set-up on alloy Crofer22APU used in stack testing. The measurement was carried out by placing the interconnect between two SOFConnex current collectors [21] and two LSM pellets (Fig. 3). Platinum paste is applied on the outer surfaces of the pellets to improve current collection between platinum mesh and the pellets. The samples are placed in an oven, the same pressure as used in stack testing is applied to the interconnect samples $(40 \mathrm{kPa})$. A constant current of $1 \mathrm{~A}$ is applied to the samples between both $\mathrm{Pt}$ meshes during the whole test duration, the samples being of ca. $3 \mathrm{~cm}^{2}$. The resistance measured is the total resistance of the pellets, current collectors and interconnect oxide layers. The resistance of the pellets and the current collectors has been measured separately at different temperatures to subtract their contribution.

The test has been carried out for more than $1300 \mathrm{~h}$ in total with different phases summarized in Table 2.

Table 2

Conductivity test on interconnect: history of the test

\begin{tabular}{lllcl}
\hline Phase & Temperature $\left({ }^{\circ} \mathrm{C}\right)$ & Time length $(\mathrm{h})$ & Total time $(\mathrm{h})$ & Remarks \\
\hline 1 & 795 & 580 & 580 & - \\
2 & 820 & 230 & 810 & - \\
3 & 845 & 230 & 1040 & Two general current failures \\
4 & 748 & 300 & 1340 & Temperature drift from 745 to $752^{\circ} \mathrm{C}$ \\
\hline
\end{tabular}




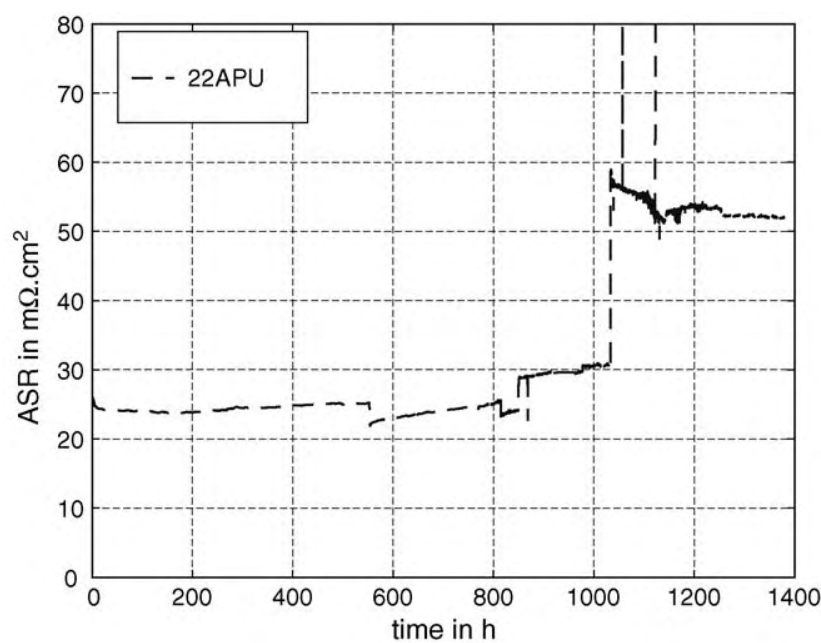

Fig. 4. Conductivity measured on the interconnects.

The behavior of the conductivity for the measured interconnects is shown in Fig. 4. At $795^{\circ} \mathrm{C}$, after more than $500 \mathrm{~h}$, the rate of increase of the resistivity is close to zero. The furnace temperature increase causes the resistance to decrease in the short term as the oxide scale conductivity is dependent on temperature. The rate of increase of the resistance increases as well. After more than $1000 \mathrm{~h}$ of exposure to high temperature, the temperature has been decreased to ca. $750^{\circ} \mathrm{C}$ and the conductivity was stable. From this test, the activation energy for the oxide scale has been identified on the assumption that the effect of the scale thickness increase during the temperature change is negligible (the furnace temperature change takes less than $1 \mathrm{~h}$ ) compared to the change in the conductivity with the temperature. The activation energy for the conductivity for the oxide scale estimated from the measurement is of $75.2 \mathrm{~kJ} \mathrm{~mol}^{-1}$ which is in agreement with the literature where $86.2 \mathrm{~kJ} \mathrm{~mol}^{-1}$ is reported for the activation energy of a spinel scale [20].

To determine the conductivity of the scale and the parameter for the rate of increase of the scale, results from measurements presented in Fig. 2 are used. The oxide scale composition on interconnect Crofer22APU has been analyzed and the depth of the scale determined. The thicknesses measured and the corresponding area specific resistance are reported in Table 3. For Crofer22APU, the scale thickness measured in our case is larger than the one reported in ref. [17], ca. $78 \mu \mathrm{m} / 8 \mu \mathrm{m}$ after $1800 \mathrm{~h}$ of exposure.

The value of $220 \mathrm{~kJ} \mathrm{~mol}^{-1}$ has been used in the following. Estimation of the activation energy $E_{\mathrm{ox}}$ from the measurements shown in Fig. 4 using the expression:

$\frac{\partial\left(\mathrm{ASR}^{2}\right)}{\partial t}=\frac{k_{\mathrm{g}}^{\circ}}{\left(\chi \rho_{\mathrm{ox}} \sigma_{\mathrm{ox}}^{0}\right)^{2}} T^{2} \exp \frac{-E_{\mathrm{ox}}+2 E_{\mathrm{el}}}{R T}$

derived from Eqs. (3), (1) and (4) was too uncertain.

\section{Model for anode reoxidation risk}

Anode supported cells rely on the anode composed of Ni/YSZ cermet as mechanical support for the electrolyte. Owing to this anode support, the cells are sensitive to redox cycling. Depending on the manufacturer, the anode thickness ranges from $200 \mu \mathrm{m}$ to $2 \mathrm{~mm}$ while the electrolyte is between 5 and $20 \mu \mathrm{m}$ thick. The cells are mounted in the stacks in oxidized state. The start-up procedure includes therefore a reduction step. During this first reduction, the microstructure of the anode changes when nickel oxide is reduced to metallic nickel and the porosity increases. No contraction of the anode is observed for a fine structured anode [22]. If the reduced cell is exposed to an oxidative atmosphere, reoxidation and a small expansion (on the order or $1 \%$ ) occur [22]. This expansion can create cracks in the electrolyte, in the complete cell, and lead to cell failure [23,22]. The micro-cracks cause gas cross-over decreasing OCV. The stacks show strong failure probabilities in case of fuel shortage for a limited time, even if they are not loaded. Anode stability is also a problem for the start-up and shut-down procedures. Redox stability of cells is a key reliability problem for intermediate temperature SOFC.

Local anode reoxidation can occur during operation as well. At high fuel utilization, the partial pressure of fuel can locally be close to zero. In case of strong fuel depletion, the fuel atmosphere is no longer reductive and conditions for a local reoxidation of the anode can be encountered. On tested cells, local oxidation has been observed (e.g. Fig. 5). A simple model to compute the equilibrium of the $\mathrm{Ni} / \mathrm{NiO}$ reaction is assumed. Implemented in a repeat element or a stack model, it allows the prediction of anode reoxidation risk. The equilibrium of $\mathrm{Ni} / \mathrm{NiO}$ has been previously studied, demonstrating good agreement between thermodynamics and the measured reversible voltage of the reaction by cyclic voltammetry $[24,25]$. The redox reaction for the $\mathrm{Ni} / \mathrm{NiO}$ oxidation is simply:

$\mathrm{Ni}(\mathrm{s})+0.5 \mathrm{O}_{2} \rightarrow \mathrm{NiO}(\mathrm{s})$

The equilibrium condition for this reaction can be computed from the thermodynamic data reported in Table 4: the partial pressure of oxygen at equilibrium is computed directly from the Gibbs free enthalpy of reaction (Eq. (7)). Fig. 6 plots the

Table 3

Parameters for the oxide scale, activation energy of the oxide scale growth assumed to be $220 \mathrm{~kJ} \mathrm{~mol}^{-1}$

\begin{tabular}{|c|c|c|c|c|c|c|c|c|}
\hline Sample & Time exposed (h) & Temperature $\left({ }^{\circ} \mathrm{C}\right)$ & Scale thickness $(\mu \mathrm{m})$ & $\operatorname{ASR}\left(\mathrm{m} \Omega \mathrm{cm}^{2}\right)$ & $k_{\mathrm{p}}\left(\mathrm{cm}^{2} \mathrm{~s}^{-1}\right)$ & $k_{\mathrm{g}}\left(\mathrm{g}^{2} \mathrm{~cm}^{-4} \mathrm{~s}^{-1}\right)$ & $\sigma_{\mathrm{ox}}^{0}\left(\mathrm{~S} \mathrm{~cm}^{-1}\right)$ & $k_{\mathrm{p}}^{\circ} \mathrm{cm}^{2} \mathrm{~s}^{-1}$ \\
\hline 22APU & 1130 & 810 & $\sim 10$ & 15.3 & $2.45 \times 10^{-13}$ & $6.66 \times 10^{-13}$ & $3.2 \times 10^{5}$ & 0.0126 \\
\hline $\mathrm{T} 458$ & 1361 & 810 & $\sim 4$ & 33 & $3.27 \times 10^{-14}$ & $8.89 \times 10^{-14}$ & $6.2 \times 10^{4}$ & 0.0016 \\
\hline
\end{tabular}

The activation energy for the oxide scale conductivity is assumed to be equivalent for the T458 as for the $22 \mathrm{APU}$ (value of $75.2 \mathrm{~kJ}$ mol ${ }^{-1}$ ). 


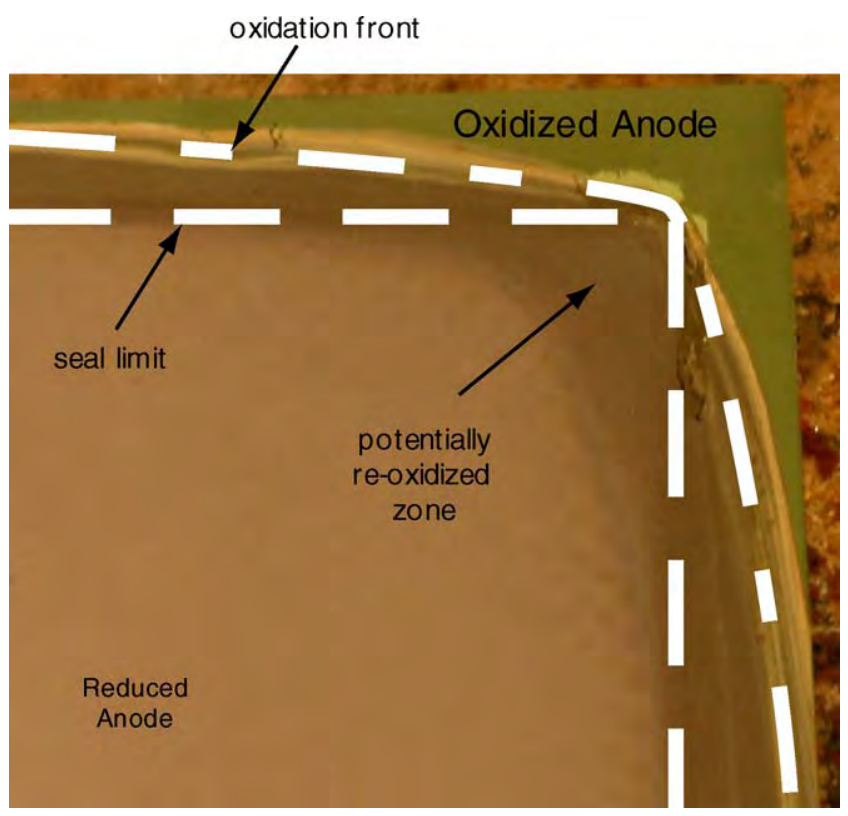

Fig. 5. Reoxidized area in the corner of the cell.

Table 4

Thermodynamic data used for the $\mathrm{Ni} / \mathrm{NiO}$ system

\begin{tabular}{llll}
\hline$\Delta H_{\mathrm{NiO}}^{\mathrm{f}} \mathrm{J} \mathrm{mol}^{-1}$ & $S_{\mathrm{O}_{2}}^{\circ} \mathrm{J} \mathrm{mol}^{-1} \mathrm{~K}^{-1}$ & $S_{\mathrm{Ni}}^{\circ} \mathrm{J} \mathrm{mol}^{-1} \mathrm{~K}^{-1}$ & $S_{\mathrm{NiO}}^{\circ} \mathrm{J} \mathrm{mol}^{-1} \mathrm{~K}^{-1}$ \\
\hline$-244 \times 10^{3}$ & 205 & 30.14 & 38.60
\end{tabular}

equilibrium value of oxygen partial pressure in the temperature range from 650 to $1000^{\circ} \mathrm{C}$.

$p_{\mathrm{O}_{2}}^{\mathrm{eq}}=\mathrm{e}^{2 \Delta G_{\mathrm{Ni} / \mathrm{Nio}}^{\circ} / R T}$

At high water vapor concentration, conditions can become oxidizing. The partial pressure of oxygen on the fuel side is computed from the local Nernst potential and the local hydrogen and water concentrations.

$U_{\text {Nernst }}=\frac{R T}{4 F} \ln \frac{P_{\mathrm{O}_{2}}^{\text {cathode }}}{P_{\mathrm{O}_{2}}^{\text {anode }}}$

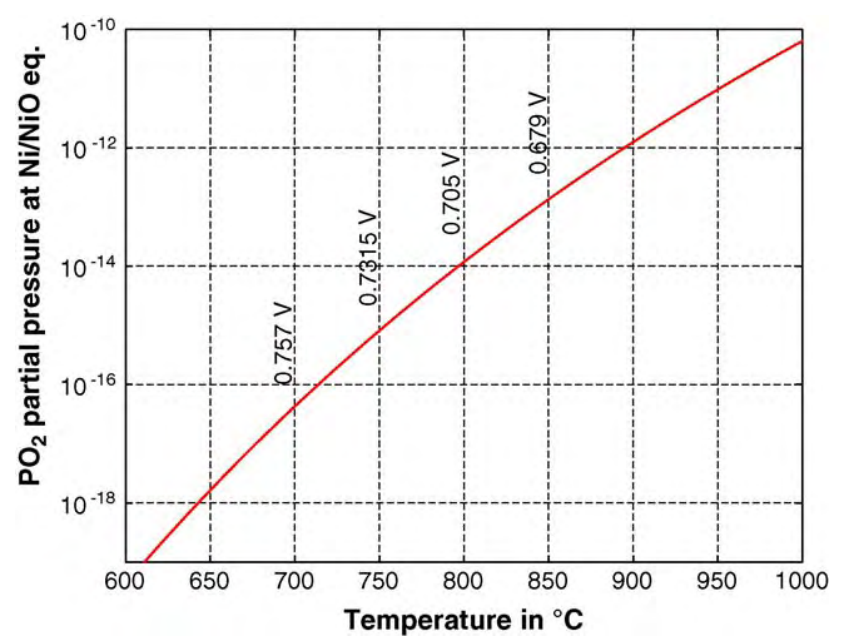

Fig. 6. Oxygen partial pressure at $\mathrm{Ni} / \mathrm{NiO}$ equilibrium.
For partial pressure of oxygen higher than the equilibrium partial pressure, the anode is at risk to be reoxidized. The kinetics of the reaction are not considered in this study although some work is published on the subject [26]. The reoxidation risk indi-

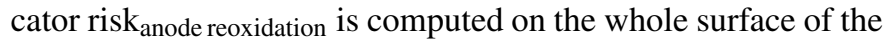
cell as follows:

risk $_{\text {anode reoxidation }}=p_{\mathrm{O}_{2}}^{\text {eq }}-p_{\mathrm{O}_{2}}^{\text {anode }}$

Reoxidation is likely to occur if the oxygen partial pressure on the anode $p_{\mathrm{O}_{2}}^{\text {anode }}$ side is superior to the $\mathrm{Ni} / \mathrm{NiO}$ equilibrium partial pressure $p_{\mathrm{O}_{2}}^{\text {eq }}$, i.e. when $p_{\mathrm{O}_{2}}^{\text {anode }}>p_{\mathrm{O}_{2}}^{\text {eq }}$. Using the reoxidation criteria risk anode reoxidation, this reoxidation condition is defined as satisfied when:

risk $_{\text {anode reoxidation }}<0$

In summary, the thermodynamic conditions for the reoxidation of the anode are encountered when the indicator risk $_{\text {anode reoxidation is negative. In the present model, as diffusion }}$ transport in the anode thickness is neglected, the indicator may underestimate the reoxidation potential. As a concentration gradient can exist in the anode thickness, the area subject to anode reoxidation is probably larger than the computed area with the present model as the local concentration close to the electrolyte thickness is lower than the mean concentration.

\section{Stack degradation simulation}

Different flow designs considered are shown in Fig. 7. The stack and repeat element model, implemented in gPROMS, is based on a $2 \mathrm{D}$ flow field description and volume averaging for the solid energy equations [27-29] where radiative boundary conditions are applied on the faces of the stack (border of the cells and the first and last repeat element). Degradation is temperature activated as the diffusion of oxygen at the interconnect interface increases with temperature. Therefore, the degradation rate is expected to be mostly dependent on stack temperature. The local temperature in the repeat element and stack is far from being homogeneous and the consequences of degradation on current density distribution are studied.

Simulation is carried out under adiabatic and non-adiabatic boundary conditions, at a reference flow rate of $300 \mathrm{ml} \mathrm{min}^{-1}$ of hydrogen. Differences in operation mode are studied. The interconnect considered in the following is Crofer22APU.

Different criteria for degradation of a repeat element are expressed as:

- the degradation percentage of power output between initial and final state:

$$
\operatorname{deg}_{\text {power }}=\frac{E_{\mathrm{e}}\left(t_{\mathrm{f}}\right)-E_{\mathrm{e}}\left(t_{\mathrm{o}}\right)}{E_{\mathrm{e}}\left(t_{\mathrm{o}}\right)}
$$

- the percentage of apparent area specific resistance increase, i.e. the slope of the $i V$ curve for the repeat element or the stack:

$$
\operatorname{deg}_{\mathrm{AASR}}=\frac{\operatorname{AASR}\left(t_{\mathrm{f}}\right)-\operatorname{AASR}\left(t_{\mathrm{o}}\right)}{\operatorname{AASR}\left(t_{\mathrm{o}}\right)}
$$




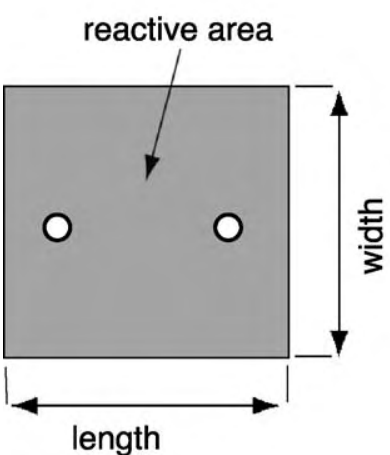

Counter-flow stack

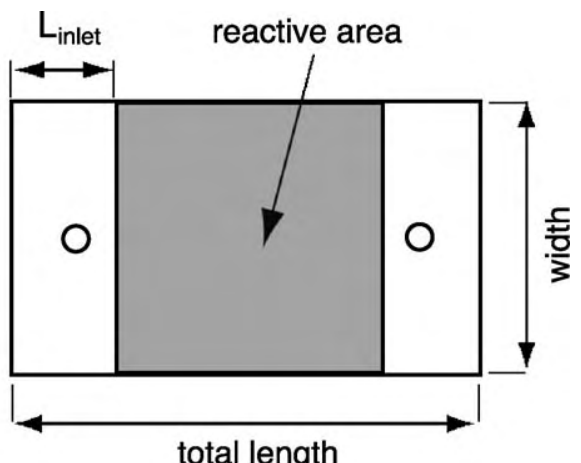

Coflow stack

Fig. 7. Scheme of the counter-flow and coflow repeat element geometry considered. The active area is the surface where the cathode is screen-printed. For the coflow case, the inlet and outlets are surrounded by zones that will not contribute to the fuel conversion.

Degradation rates are often expressed as rate of power output decrease per time unit. This criterion is clear and useful. However, when comparing experiments carried out at the same current density and not at the same cell potential, one has to be carefully in the consistency of the comparison.

\subsection{Repeat element degradation: base case}

The base configuration is that of a counter-flow repeat element $\left(50 \mathrm{~cm}^{2}\right.$ active area) operated with $300 \mathrm{ml} \mathrm{min}^{-1}$ hydrogen and an air ratio of 3 . The repeat element is assumed to be operated in galvanostatic mode (at $24 \mathrm{~A}$ ). The case has been tested in adiabatic and non-adiabatic boundary conditions. The furnace temperature was set to $750{ }^{\circ} \mathrm{C}$.

The cell potential as a function of time is plotted in Fig. 8, the power output degradation being of 19.5 and $11.8 \%$ (for 10,000 h) for the adiabatic and non-adiabatic cases, respectively. Degradation rates decrease with time as the oxide layer growth follows a parabolic law. The difference in degradation rate is explained by the temperature profile difference in the two cases: the adiabatic case operates at an averaged temperature of ca. $900^{\circ} \mathrm{C}$, while

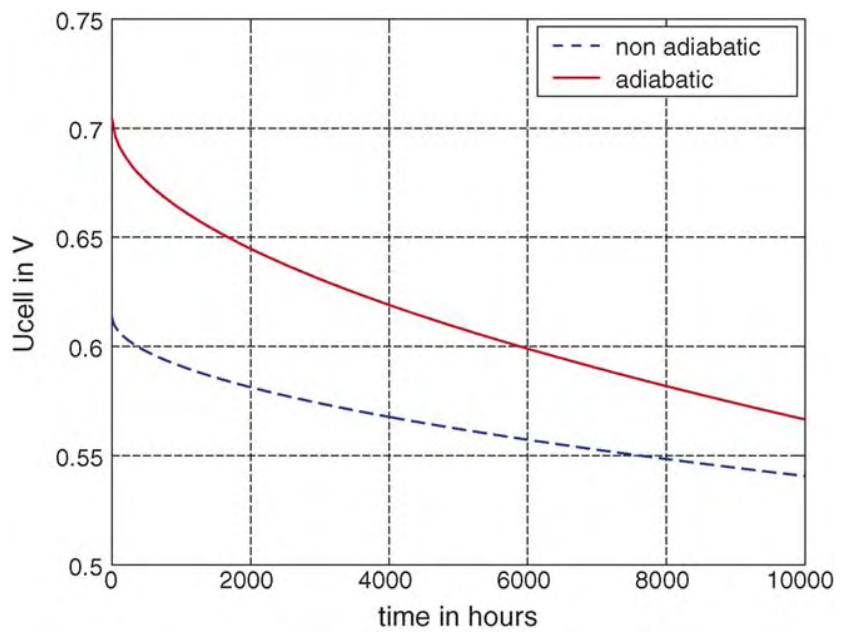

Fig. 8. Potential evolution at $70 \%$ fuel utilization for a repeat element in adiabatic and non-adiabatic boundary conditions. it reaches only $800^{\circ} \mathrm{C}$ for the non-adiabatic case. The degradation is obviously explained by the increase in ohmic resistance. As temperature is not homogeneous on the active surface of the cell, the rate of growth of the oxide scale is not homogeneous. Therefore, the local resistance distribution (sum of all losses) changes on the surface. Fig. 9 shows the initial and final total

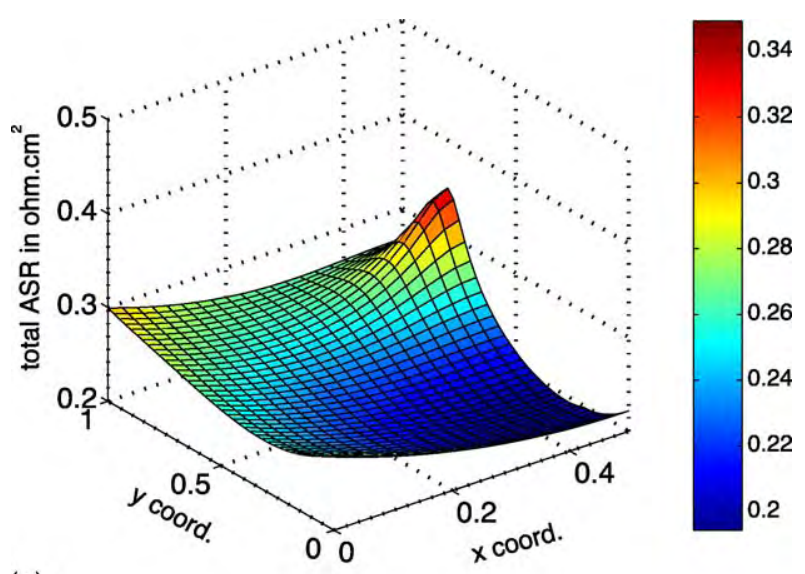

(a)

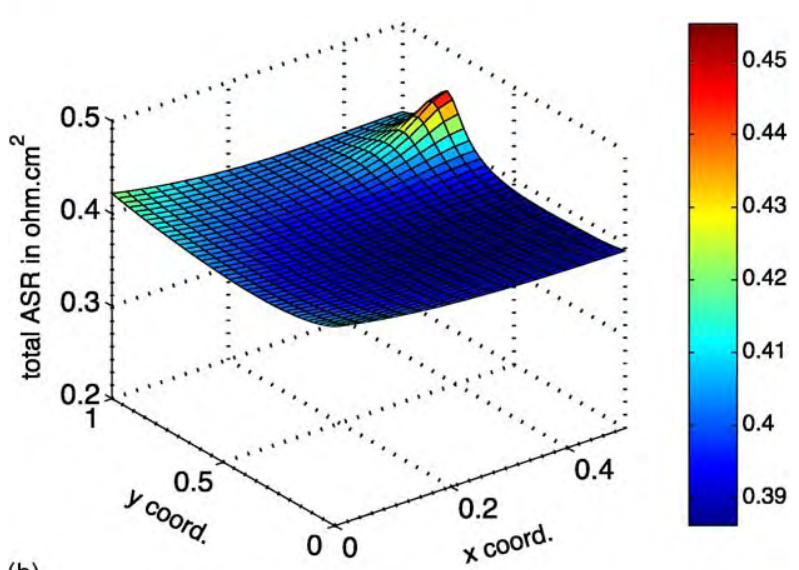

Fig. 9. Degradation, evolution of the current density distribution and of the potential with time: (a) initial local ASR profile on the repeat element and (b) final local ASR profile on the repeat element. 

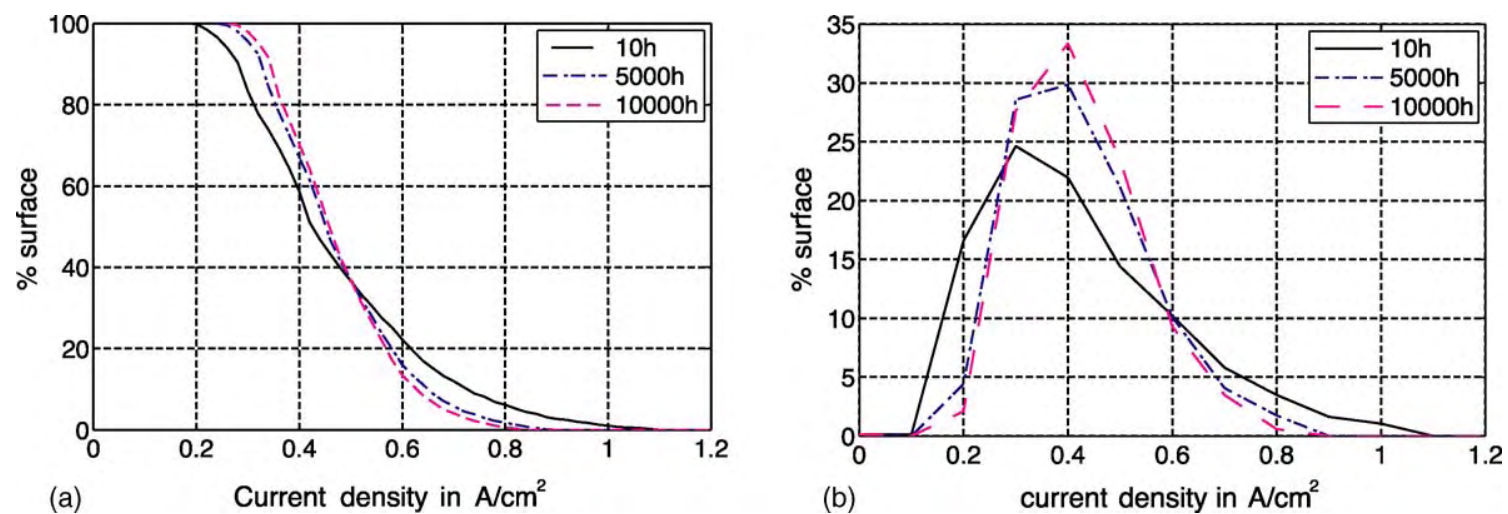

Fig. 10. Degradation and evolution of the current density distribution with time on the counter-flow design: (a) classified current density at $t=50 \mathrm{~h}, t=5000 \mathrm{~h}$ and $t=10,000 \mathrm{~h}$ and (b) current density distribution at $t=50 \mathrm{~h}, t=5000 \mathrm{~h}$ and $t=10,000 \mathrm{~h}$.

resistance profile for the adiabatic case. Initially, in Fig. 9(a), the total local resistance is a function of the temperature only, the minimum resistance locations corresponding to the regions with the maximum temperatures (with total resistances of $0.25 \Omega \mathrm{cm}^{2}$ minimally and $0.35 \Omega \mathrm{cm}^{2}$ maximally). The final state shown in Fig. 9(b) is a function of the repeat element history of operation and temperature, the profile being here almost homogeneous with values in the range of $0.39-0.46 \Omega \mathrm{cm}^{2}$. Initially, the interconnect ohmic resistance represents $6 \%$ of the losses while after $10,000 \mathrm{~h}$ it amounts to $40 \%$ of the total losses.

The change in resistance distribution affects the current density distribution. In Fig. 10( $a$ and $b$ ), the classified current density (representing the fraction of the cell surface having a current density larger than $x \mathrm{~A} \mathrm{~cm}^{-2}$ ) and the current density distribution are shown for the initial state, after 5000 and $10,000 \mathrm{~h}$. The maximum current density decreases from $1.1 \mathrm{~A} \mathrm{~cm}^{-2}$ to less than $0.9 \mathrm{~A} \mathrm{~cm}^{-2}$ in the final state, the minimum values tending to increase. In this counter-flow case, the current density distribution profile tends to be more homogeneous with progressing degradation: the maximum temperature area is the same as the maximum current density area in this case and therefore oxidation of the interconnects occurs preferentially in this area. This effect is seen in the non-adiabatic case as well. However, as the temperature differences as well as the degradation rate becomes smaller, differences in the distributions become smaller too.

Degradation has been simulated for the coflow case as well. The trend is the same as for the counter-flow repeat element, in a constant current mode the potential decreases with time. However, for the same operating conditions, owing to lower temperatures in the repeat element, the degradation rate is significantly lowered.

\subsection{Sensitivity to operating parameters and to design variables}

Local temperature defines the local degradation rate. As the temperature field is dependent on the operating parameters and the decision variables for the repeat element design (thicknesses, area, air excess ratio), the impact of these decision variables on the degradation behavior is considered. Sensitivity analyses have been performed for the following cases:

- for a counter-flow repeat element, with a fixed geometry (base case) and fixed flow rates $\left(300 \mathrm{ml} \mathrm{min}^{-1}\right.$ fuel and air ratio 3 ), the furnace temperature and the current output has been varied;

- for a coflow case, the same variations have been performed (with the same cell area and flow-rates as for the counterflow);

- for a counter-flow repeat element, with a fixed flow rate and current output, the design decision variables such as cell area, interconnect thickness, air channel height and air stoichiometric ratio have been varied.

The sensitivity of the degradation rate to these variables can therefore be defined. In Fig. 11(a), the geometry is fixed (cell area, interconnect thickness) as well as the flow rates while the current output and the furnace temperature are varied. The degradation rate expressed as deg $_{\mathrm{AASR}}$ is plotted as a function of the fuel utilization and the mean temperature on the surface. The degradation shows a clear linear trend with the mean temperature in the solid. The sensitivity to the fuel utilization (or to the current density) is small. In Fig. 11(b), the same total current and fuel flow rate has been applied to all the cases while the cell area and interconnect thickness have been varied. These design variations induce a change in the power density per unit area and unit volume that result in different temperature profiles. The figure shows the degradation rate as a function of the current density and the mean temperature in the solid. Again the degradation rate is a linear function of the mean temperature in the solid while the sensitivity to the current density is low. The results are here the degradation expressed with $\operatorname{deg}_{\text {AASR }}$ and not with deg $_{\text {power }}$. With this last criteria, the degradation present a dependence to the current density; yet, this is partly explained by the change in the initial cell potential that decreases with the increasing current density and is not related to the degradation phenomena considered here. Finally, the results for all sensitivity cases are summarized in Fig. 12. A linear trend between the mean temperature in the repeat element and the degradation rate 

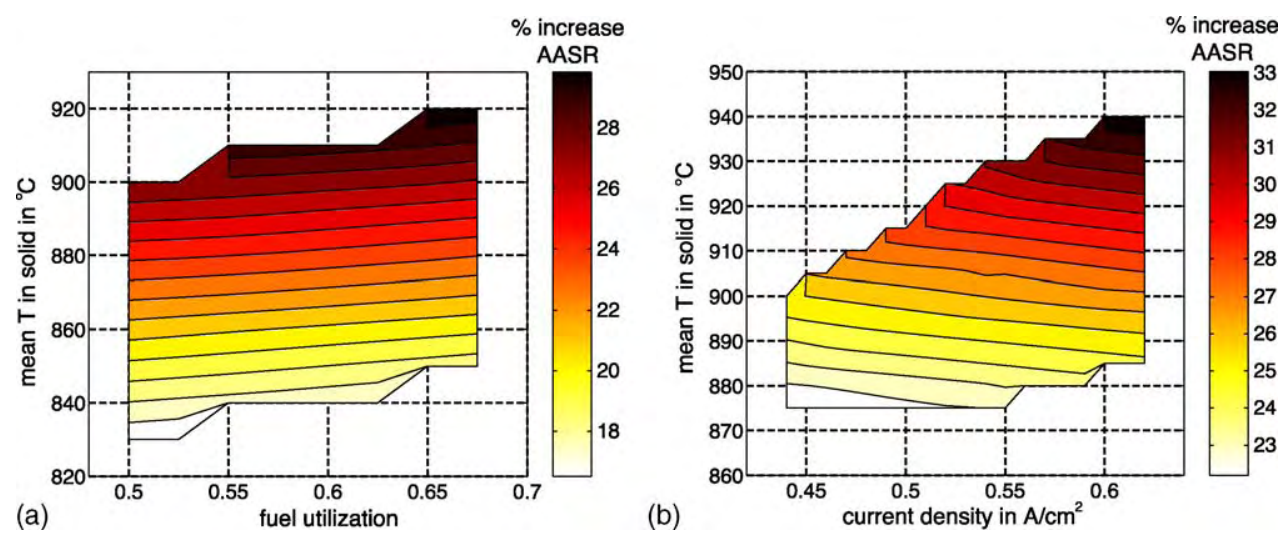

Fig. 11. Sensitivity of degradation to design and operating decision variables: (a) degradation for same design (counter-flow) with changing operating parameter (furnace temperature, current density) and (b) degradation for the counter-flow at the same total current and furnace temperature with changing design decision variables (cell area, interconnect thickness).

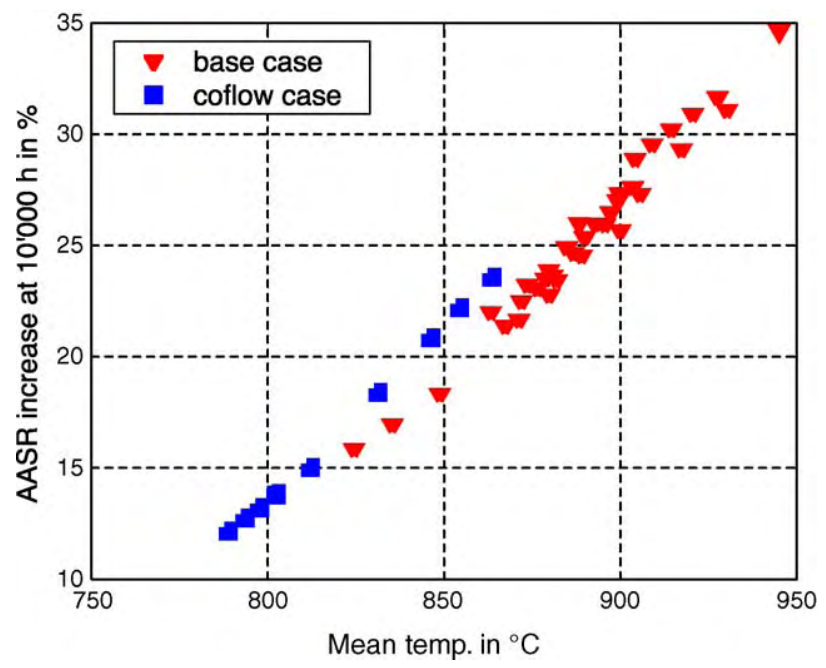

Fig. 12. Degradation rate expressed as AASR increase for all simulated cases (coflow and counter-flow-design variations and operating parameters variations).

(expressed in $\operatorname{deg}_{\text {AASR }}$ ) is established. This linear trend is valid for different operating conditions, current densities and even different repeat element configurations. The use of this criterion to express the degradation of stack performances is therefore recommended as it allows the comparison of results even if the conditions or initial performances are not the same.

\subsection{Stack degradation behavior}

Long term behavior of 5, 15 and 30 cell-stacks has been simulated in the same conditions $\left(300 \mathrm{ml} \mathrm{min}^{-1}\right.$ fuel, $750{ }^{\circ} \mathrm{C}$ furnace temperature, lambda 3 and $24 \mathrm{~A}$ ) for $10,000 \mathrm{~h}$ of operation. Owing to the stack temperature gradient in the stacking direction, cell degradation is expected to be different in the stack center compared to the behavior at the stack extremes.

The different simulations performed exhibit a larger degradation rate for the cell in the center when compared to cells at the extremes. The degradation rate follows the temperature profile on the height of the stack. This is clearly seen in Fig. 13(a) where the cells in the stack center (30 cells stack) have a degradation between initial and final state of more than $11 \%$ while on the extremes the rate is around 9\%. Maximum degradation is shifted to cell \#17 as in the model the air is fed from cell \#1 and is heated along its path; the maximum temperature is therefore not exactly in the stack middle (\#15). This trend is confirmed by the degradation/activation behavior of a tested stack of 29 cells: the stack was operated in galvanostatic mode at $13 \mathrm{~A}$ during $44 \mathrm{~h}$ at the beginning of the test. In Fig. 13(b), the cell potential vari-
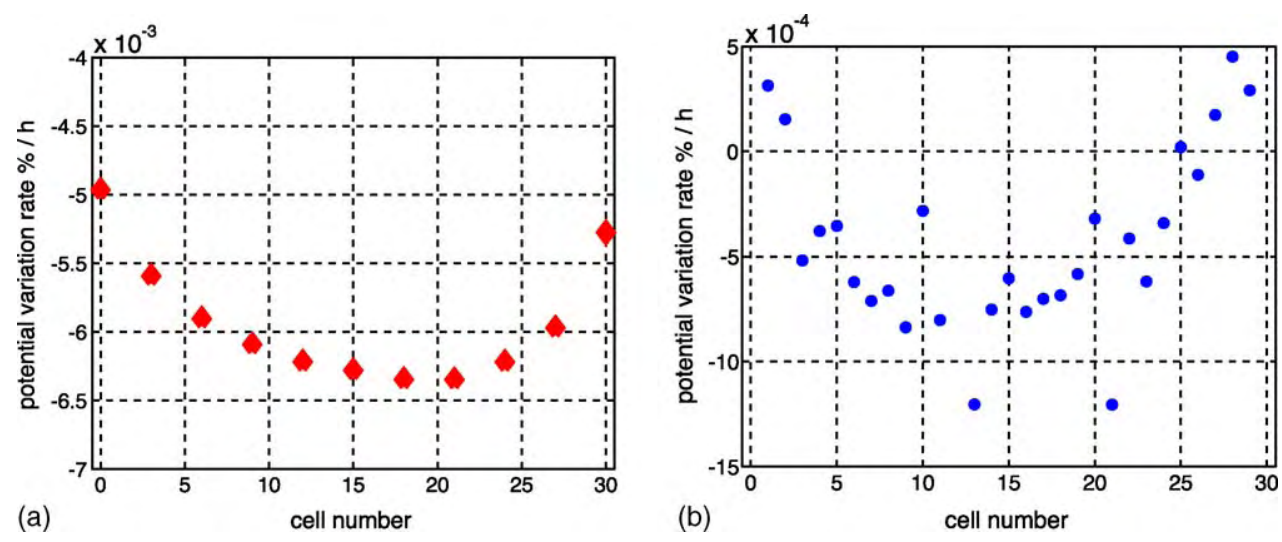

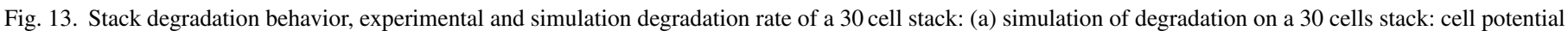
variation rate at $80 \mathrm{~h}$ and (b) experimental degradation rate per hour on a 29 cells stack: cell potential variation rate at $80 \mathrm{~h}$. 
Table 5

Stack degradation results, initial and final cell potential

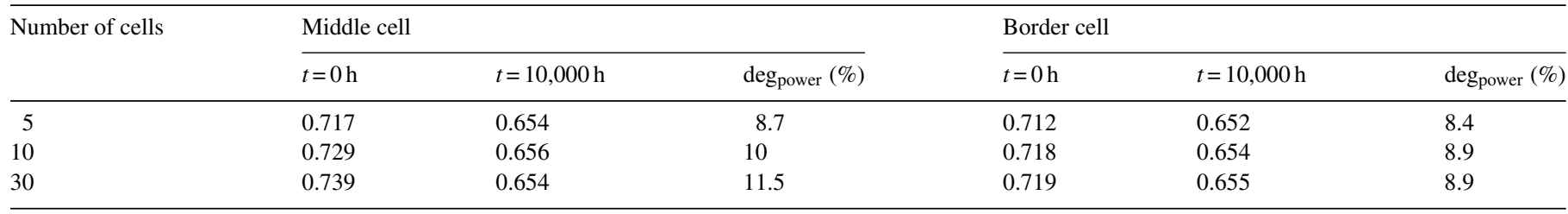

ation rate with time is shown for each of the cells in the stack: on the border of the stack the potentials are increasing while in the middle of the stack the potentials are decreasing. This rate of change is determined by both the activation and the degradation phenomena. At the extremes of the stack, activation is still dominating while in the stack center degradation has overcome activation and a net degradation is measured. For the experimental case, the shift in the maximum temperature is towards cell \#1, explained by the test configuration: air is fed from both ends (for flow rate distribution reasons) and cell \#1 was on top of the stack. As combustion gases are lighter than air, they are expected to go towards the top of the stack.

In Table 5, simulated degradation rates for stacks of 5, 10 and 30 cells are reported for the cell in the middle of the stack and the cell at the border. The degradation rate of the center cells increases significantly with the number of cells from $8.7 \%$ for a 5 cells stack to $11.5 \%$ for a 30 cells stack. For the border cells, the degradation rate is almost constant with the number of cells. This is explained by the strong heat loss at the stack extremes that prevents the temperature level to rise significantly with the number of cells (see in refs. [27,29]). This non-homogeneous degradation rate could lead to modify the cell potential profile along the height of the stack; initially, owing to the temperature distribution, the cells in the middle are performing better than the cells on the border but degradation leads to a quasi homogeneous profile for $10,000 \mathrm{~h}$.

\subsection{Comparison with experiment}

A repeat element has been tested for more than $5000 \mathrm{~h}$ (Fig. 14). This test was performed with T458 interconnects of

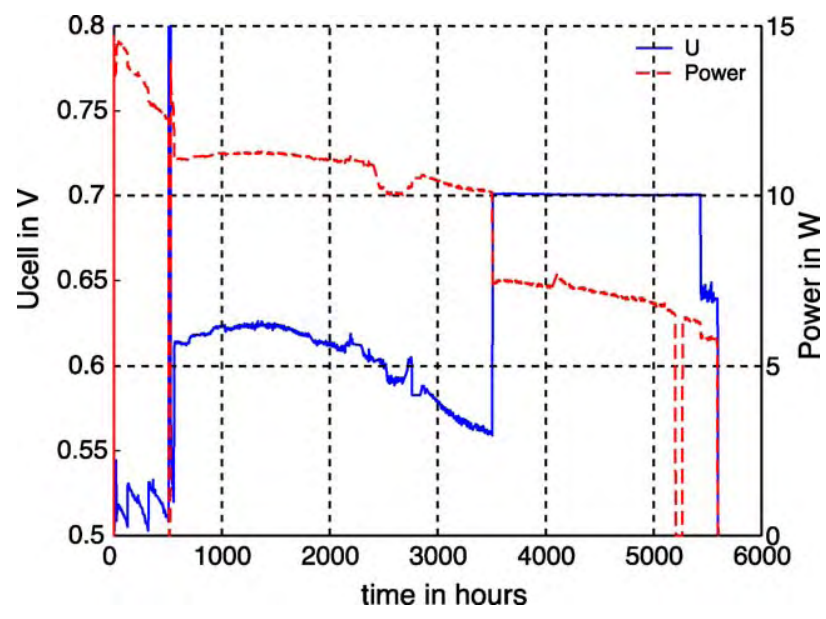

Fig. 14. Long term test on a repeat element \#MS21.

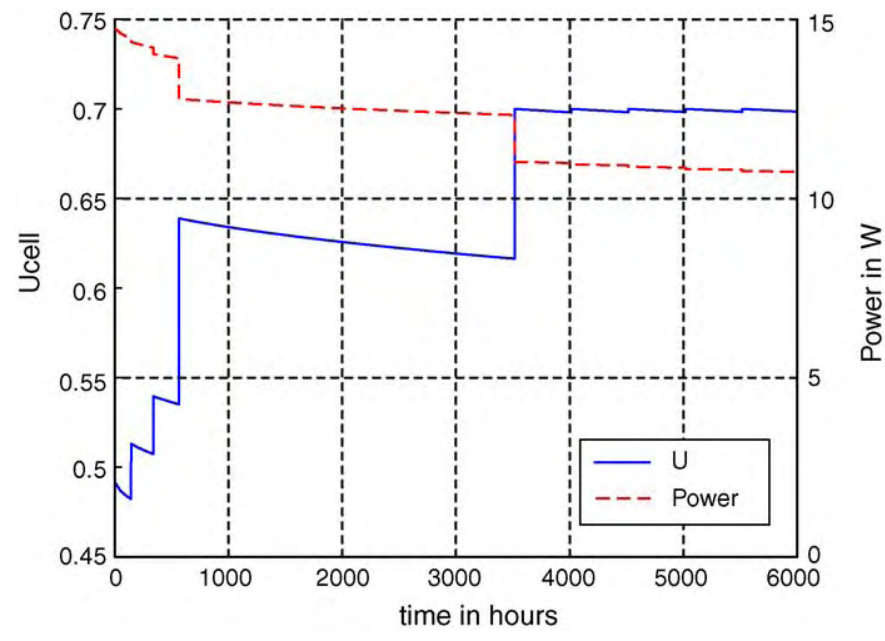

Fig. 15. Simulation of the \#MS21 repeat element test of Fig. 14.

$0.75 \mathrm{~mm}$ thick. The model has been used to simulate the behavior of repeat element degradation in the same test conditions (furnace temperature of $770{ }^{\circ} \mathrm{C}$, a fuel flow rate of $500 \mathrm{ml} \mathrm{min}^{-1}$ and an air ratio of 3 ).

The simulation (see Fig. 15) includes only the interconnect degradation behavior. Therefore, the strong activation measured between $t=500$ and $1300 \mathrm{~h}$ is not reproduced. Nevertheless, the strong degradation in the first $500 \mathrm{~h}$ as well as the general trend is reproduced. The simulated degradation is not as important as the measured one as the only effect accounted for in the simulation is the interconnect degradation. In an experiment, the degradation observed comes from both the interconnect and the cell resulting in a larger degradation.

\section{Anode reoxidation simulation}

The anode reoxidation model has been implemented in the repeat element model to identify the critical regions and operating conditions. In previous work, the region of the fuel inlet and outlet corners has been identified as critical for the counterflow repeat element [28,30]. The operation conditions where the reoxidation appears are identified for different flow rates and furnace temperature. For each operating condition, the fuel utilization above which the anode would be reoxidized is identified.

\subsection{Counter-flow repeat element}

The electrolyte electronic conductivity is in the range of $30-40 \Omega \mathrm{cm}^{2}$. Simulations have been performed for the case of 

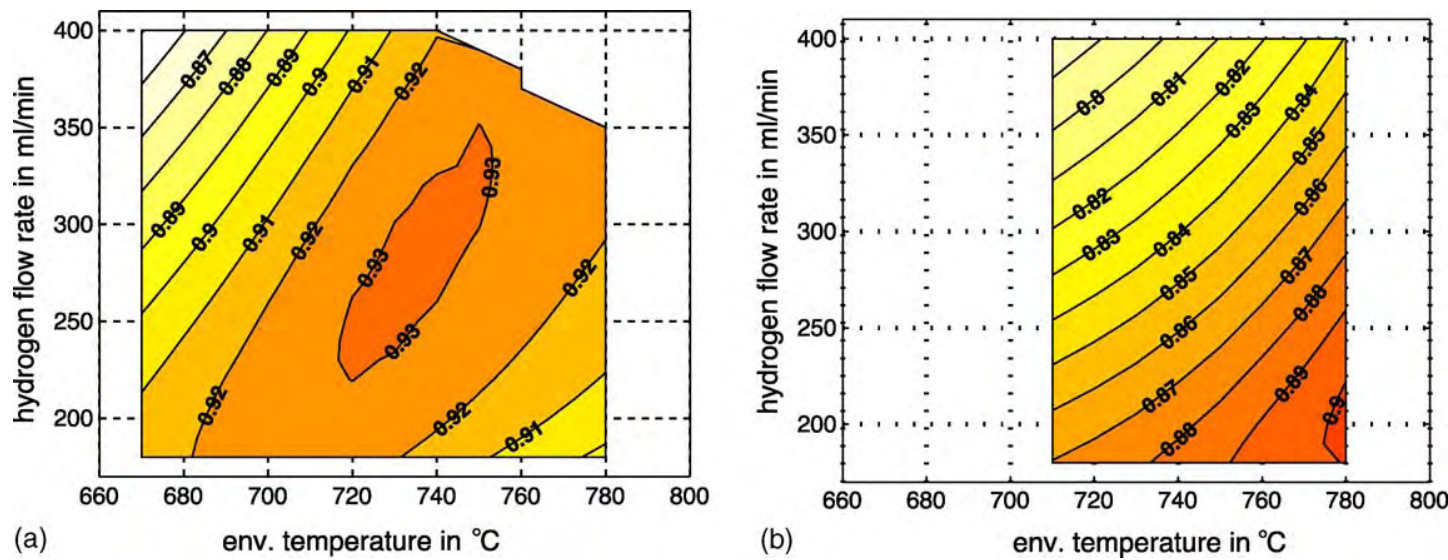

Fig. 16. Limit of possible fuel utilization as a function of furnace temperature and fuel flow rate: (a) adiabatic repeat element and (b) non-adiabatic repeat element.

a single repeat element (non-adiabatic case) and the case of a repeat element in a stack (adiabatic case). The results are presented in Fig. 16. For the adiabatic repeat element (Fig. 16(a)) operated with a furnace temperature below $710^{\circ} \mathrm{C}$ and for the non-adiabatic repeat element (Fig. 16(b)), the maximum possible fuel utilization decreases with increasing fuel flow rate. At $710{ }^{\circ} \mathrm{C}$, the limit is at $92 \%$ at $200 \mathrm{ml} \mathrm{min}^{-1}$ fuel flow rate and decreases to $89 \%$ for the adiabatic case. For the non-adiabatic case, the limit moves from 87 to $78 \%$.

With an increasing flow rate, the diffusive transport becomes relatively less important. The lean fuel concentration areas suffer from poor convective transport, at low flow rate, which is partly compensated by diffusion, but this effect becomes limited at higher flow rate. For the adiabatic case, for furnace temperatures over $720^{\circ} \mathrm{C}$ the dependence on the fuel flow rate changes, the limit increases at low flow rate while it decreases at high flow rate.

At high temperature, the reoxidation limit is higher (@ $1 \times 10^{-13} p_{\mathrm{O}_{2}}$ on the fuel side) and the trend changes. This needs to be verified, however, as the electrochemical kinetic parameters used are not considered as fully reliable, especially at high temperature.

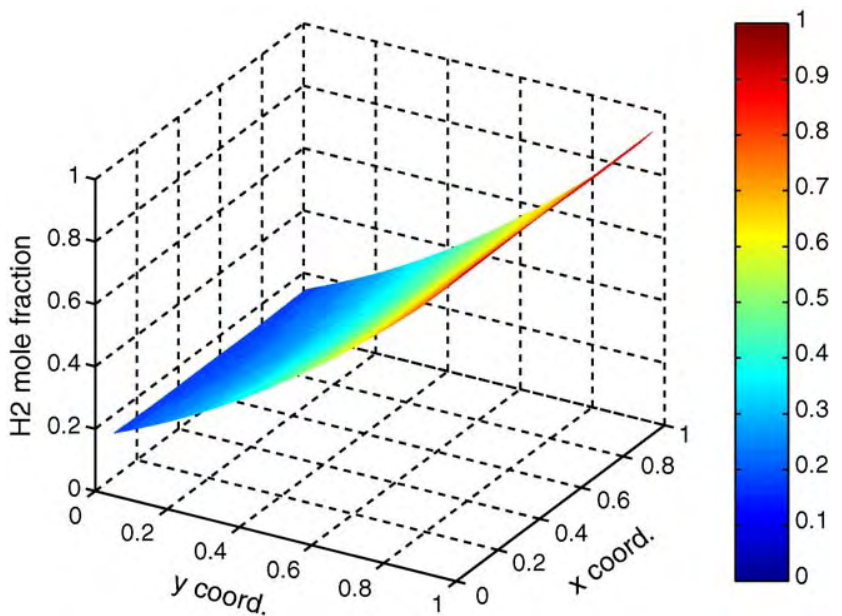

Fig. 17. Hydrogen concentration profile at $80 \%$ fuel utilization for the coflow case.

\subsection{Coflow case}

For the coflow case, the same simulations have been performed and the operation limit is simply the complete depletion of fuel. The fuel concentration is sufficiently homogeneous at the fuel outlet to avoid the anode reoxidation problem (see Fig. 17). The limitation is therefore only determined by the total fuel utilization (which depends on the effective current and the shorting current due to the electronic conductivity of the electrolyte).

\section{Conclusion}

The simulation of interconnect degradation allows to explore the impact of different operating conditions on the degradation behavior. The temperature is obviously the main factor on the degradation processes and a linear relation has been established between the mean temperature of the stack and the degradation rate if the latter is expressed as a rate of ASR increase. The use of this criterion to express degradation seems interesting as it allows to compare degradation for different operating points consistently. Other degradation processes such as the electrolyte degradation have not been included in this model. However, most of the degradation processes are thermally activated (although some like electrode degradation are current activated as well) and therefore the results of this study can be qualitatively extended to other degradation processes.

In general, the temperature in the stack should be minimized to decrease degradation rates. Therefore, an operating temperature lowered to $750{ }^{\circ} \mathrm{C}$ or lower could be beneficial.

The simulation of the anode reoxidation potential shows that for the counter-flow case, where design problems have been identified, the operation would be limited by the potential anode reoxidation caused by extreme fuel depletion in some areas. The limit of operation is dependent on the flow pattern. For the coflow case, this limitation is not predicted to occur by the model as the fuel concentration at the fuel outlet is homogeneous. On the contrary, for the counter-flow case, the tested repeat element is likely to be even more exposed to anode reoxidation. The simulated values should therefore be taken as the high limit. 
The limit in operation for a real case is probably lowered by 5 or $10 \%$. A more accurate flow model with CFD could estimate the operating limit more accurately.

However, the decrease in temperature is favorable to anode reoxidation. This is in contradiction with the degradation of the interconnect for which a lowering of the temperature is favorable. The operation window for intermediate temperature SOFC is therefore limited on the high temperature by the degradation of the interconnect (and probably other components) and on the low temperature by anode reoxidation (according to ref. [26], the reoxidation kinetics seems to be mainly governed by the diffusion processes and to present small dependence on the temperature). The operating points concerned are the points at maximum efficiency (high fuel utilization) at which the fuel cell will be operated. This anode oxidation potential should therefore be accounted for when defining the operational limits. Anode oxidation should be accounted for in the design stage to avoid any stagnation point in the fuel flow pattern. This study is preliminary and shows the potential of simulation to predict and provide information on degradation behavior. To be completed, a better characterization of the interconnect degradation at different temperatures is suitable. Interconnect degradation on the fuel side should be included. Degradation data should be collected for the electrolytes at lower temperature and if possible with a nickel-doped electrolyte, as anode supported cells are prone to modify the electrolyte composition during sintering. Electrode degradation seems difficult to implement in a near future.

On anode reoxidation, the sensitivity to the electrode performance should be carried out, preliminary results showed that the risk increases when the electrochemical performances decreases.

\section{Acknowledgements}

The Swiss Federal Energy Office (project 46795/contract 86895) and the Swiss Commission for Technology and Innovation (CTI project 5041.2SUS) are gratefully thanked for financial support. Dr. Hugh Middleton is gratefully acknowledged for the discussions on the nickel oxidation issues. Finally, Dr. Max Aeberhard from EMPA Thun (Switzerland) is acknowledged for the analysis performed on the interconnects.

\section{References}

[1] H. Yokokawa, N. Sakai, T. Kawada, M. Dokiya, Thermodynamic analysis on interface between perovskite electrode and YZS electrolyte, Solid State Ionics 40-41 (1990) 398-401.

[2] C. Clausen, C. Bagger, Bilde-Sorensen, A. Horsewell, Microstructural and microchemical characterization of the interface between $\mathrm{La}_{0.85} \mathrm{Sr}_{0.15} \mathrm{MnO}_{3}$ and $\mathrm{Y}_{2} \mathrm{O}_{3}$-stabilized $\mathrm{ZrO}_{2}$, Solid State Ionics 70-71 (1994) 59-64.

[3] H.Y. Lee, S.M. Oh, Origin of cathodic degradation a new phase formation at the $\mathrm{La}_{0.9} \mathrm{Sr}_{0.1} \mathrm{MnO}_{3} / \mathrm{YSZ}$ interface, Solid State Ionics 90 (1996) 133-140.

[4] S.P. Simner, J.P. Shelton, M.D. Anderson, J.W. Stevenson, Interaction between $\mathrm{La}(\mathrm{Sr}) \mathrm{FeO}_{3} \mathrm{SOFC}_{\text {cathode }}$ and $\mathrm{YSZ}$ electrolyte, Solid State Ionics 161 (2003) 11-18.

[5] M.J. Jørgensen, P. Holtappels, C.C. Appel, Durability test of SOFC cathodes, J. Appl. Electrochem. 4 (30) (2000) 411-418.
[6] S. Primdahl, M. Mogensen, Durability and thermal cycling of Ni/YSZ cermet anodes for solid oxide fuel cells, J. Appl. Electrochem. 30 (2000) $247-257$.

[7] H. Tu, U. Stimming, Advances, aging mechanisms and lifetime in solid-oxide fuel cells, J. Power Sources 1-2 (127) (2004) 284-293.

[8] Vels Hansen S K., K. Norrman, M. Mogensen, $\mathrm{H}_{2}-\mathrm{H}_{2} \mathrm{O}-\mathrm{Ni}-\mathrm{YSZ}$ electrode performance: effect of segregation to the interface, J. Electrochem. Soc. 9 (151) (2004) A1436-A1444.

[9] M. Hattori, Y. Takeda, Y. Sakaki, A. Nakanishi, S. Ohara, K. Mukai, J.H. Lee, T. Fukui, Effect of aging on conductivity of yttria stabilized zirconia, J. Power Sources 126 (2004) 23-27.

[10] C. Haering, A. Roosen, H. Schichl, Degradation of the electrical conductivity in stabilised zirconia systems. Part I: yttria-stabilised zirconia, Solid State Ionics 176 (2005) 253-259.

[11] A.C. Mueller, A. Weber, D. Herbstritt, E. Ivers-Tiffée, Long term stability of yttria and scandia doped zirconia electrolytes, in: S.C. Singhal, M. Dokiya (Eds.), SOFC VIII, Proceedings of the International Symposium, Electrochemical Society, 2003, pp. 196-199.

[12] S. Linderoth, N. Bonanos, K.V. Jensen, J. Bilde-Sorensen, Effect of NiO-to$\mathrm{Ni}$ transformation on conductivity and structure of yttria-stabilized $\mathrm{ZrO}_{2}$, J. Am. Ceram. Soc. 11 (84) (2001) 2652-2656.

[13] Z. Yang, K. Scott Weil, D.M. Paxton, J.W. Stevenson, Selection and evaluation of heat-resistant alloys for SOFC interconnect applications, J. Electrochem. Soc. 150 (9) (2003) A1188-A1201.

[14] K. Honegger, A. Plas, Evaluation of ferritic steel interconnect for SOFC stacks, in: S.C. Singhal, H. Yokokawa (Eds.), SOFC VII, Proceedings of the International Symposium, Electrochemical Society, vol. 16, 2001, pp. 803-810.

[15] C. Gindorf, K. Hilpert, L. Singheiser, Determination of chromium vaporization rates of different interconnect alloys by transpiration experiments, in: S.C. Singhal, H. Yokokawa (Eds.), SOFC VII, Proceedings of the International Symposium, Electrochemical Society, 2001, pp. 793-802.

[16] J.P. Abellan, V. Shemet, F. Tietz, L. Singheiser, Quaddak-ersF W.J., Ferritic steel interconnect for reduced temperature SOFC, in: S.C. Singhal, H. Yokokawa (Eds.), SOFC VII, Proceedings of the International Symposium, Electrochemical Society, 2001, pp. 811-819.

[17] Z. Yang, J.S. Hardy, M.S. Walker, X. Guanguang, S.P. Simner, J.W. Stevenson, Structure and conductivity of thermally grown scales on ferritic $\mathrm{Fe}-\mathrm{Cr}-\mathrm{Mn}$ steel for SOFC interconnect applications, J. Electrochem. Soc. 11 (151) (2004) A1825-A1831.

[18] K. Huang, P.Y. Hou, J.B. Goodenough, Characterization of iron-based alloy interconnects for reduced temperature solid oxide fuel cells, Solid State Ionics 1-4 (129) (2000) 237-250.

[19] M. Kuznecov, K. Eichler, S. Megel, O. Peter, Application of the ferritic steels for the stack fabrication, in: M. Mogensen (Ed.), Proceedings of the 6th European SOFC Forum, 2004, pp. 1573-1585.

[20] N. Sakai, T. Horita, Y. Xiong, K. Yamaji, H. Kishimoto, M.E. Brito, H. Yokokawa, T. Maruyama, Manganese-chromium-iron oxide in oxide scale of ally interconnects, in: M. Mogensen (Ed.), Proceedings of the 6th European SOFC Forum, 2004, pp. 1646-1653.

[21] M. Molinelli, D. Larrain, R. Ihringer, L. Constantin, N. Autissier, O. Bucheli, D. Favrat, J. Van herle, Current collection and stacking of anode supported cells with metal interconnects to compact repeating units, in: SOFC VIII, Proceedings of the International Symposium, Electrochemical Society, PV 2003-2007, 2003, pp. 203-212.

[22] D. Waldbillig, A. Wood, G.I. Douglas, Thermal analysis of the cyclic reduction and oxidation behaviour of SOFC anodes, Solid State Ionics 176 (2004) 847-859.

[23] G. Robert, A. Kaiser, E. Batawi, Anode substrate design for redox-stable ASE cells, in: M. Mogensen (Ed.), Proceedings of the 6th European SOFC Forum, 2004, pp. 193-200.

[24] P.H. Middleton, M.E. Seiersten, B.C.H. Steele, Morphology and electrochemistry of porous nickel/zirconia cermets, in: S.C. Singhal (Ed.), SOFC I, Proceedings of the International Symposium, Electrochemical Society, 1989, pp. 90-95.

[25] M.E. Seiersten, P.H. Middleton, Redox behavior of plasma sprayed nickel anodes, in: SOFC II, Proceedings of the International Symposium, Electrochemical Society, 1991, pp. 569-576. 
[26] N.M. Tikekar, T.J. Armstrong, A.V. Virkar, Reduction and re-oxidation kinetics of nickel-based solid oxide fuel cell anodes, in: S.C. Singhal (Ed.), SOFC VIII, Proceedings of the International Symposium, Electrochemical Society, 2003, pp. 670-679.

[27] D. Larrain, J. Van herle, M. Graetzel, D. Favrat, Modeling of cross-flow stack: sensitivity to thermal properties of the materials, in: Proceedings of the 8th SOFC International Symposium, edited by the Electrochemical Society, PV 2003-2007, 2003, pp. 14781486 .
[28] D. Larrain, J. Van herle, F. Maréchal, D. Favrat, Generalized model of planar SOFC repeat element for design optimization., J. Power Sources 1-2 (131) (2004) 304-312.

[29] D. Larrain, Solid oxide fuel cell stack simulation and optimization, including experimental validation and transient behavior, $\mathrm{PhD}$ thesis, Ecole Polytechnique Fédérale de Lausanne, 2005. http://library.epfl.ch/ theses/?nr=3275.

[30] N. Autissier, D. Larrain, J. Van herle, D. Favrat, CFD simulation tool for solid oxide fuel cells, J. Power Sources 1-2 (May (131)) (2004) 313-319. 